\title{
RESEARCH ON THE ANCIENT MONGOLIAN PLACE-NAME ALONG THE SILK ROAD
}

\author{
Nashunwuritu ${ }^{\mathrm{a}}$, Baiyinbateer, ${ }^{\mathrm{b}}$ Duoxi ${ }^{\mathrm{b}}$ \\ a Inner Mongolia University, Hohhot 010021, China - (qingjirvm@126.com); \\ ${ }^{\text {b } C h i f e n g ~ M u n i c i p a l ~ P e o p l e ' s ~ C o n g r e s s, ~ C h i f e n g ~ 024000, ~ C h i n a ~-~(b y b t e r @ 126 . c o m ; ~ c f d u o x i @ ~ 163 . c o m) ; ~}$
}

Commission IV, WG IV/2

KEY WORDS: Ancient Silk Road; Mongolian; Place Names; Culture Integration

\begin{abstract}
:
"Silk Road" is an ancient commercial trade channel connecting China with Asia, Africa and Europe and a major link of the economy, politics and culture of the East and West as well. In the 13th Century, with the westward expedition of Mongolian, the communication and integration of culture among different countries was accelerated, which led to many Mongolian place-names scattered in the countries along the silk-road, such as Khwarezmia, Armenia, Mesopotamia, Kipchak, Persian, involving today's Russia, Poland, Ukraine, Bulgaria, Hungary, Austria, Italy, Serbia, Syria, Iran, Afghanistan, Iraq, Uzbekistan, Turkmenistan, India and many other countries and regions. The place-name is a kind of important factor that can represent the changes of culture, economic in history. We analyzed the current place-names in different countries or regions with different language to find out ancient Mongolian place-names, and marked the names on the digital map. Through the changes and transition of the place-name, we explored the development of Mongolian language changes itself, Mongolian blends with other languages, and furtherly reveal information of culture exchange.
\end{abstract}

\section{BACKGROUND}

The study of Mongolian place names is an emerging subject of Mongolian culture studies. In China the study of Mongolian place names started later than the study of traditional Mongolian linguistics, literature and history. The study of the culture of place names can reveal the cultural connotation of the place names, as well as the social and economic development in the related geographic places. Currently, more and more researchers have focused their studies on the Mongolian place names culture, trying to analyse the relationships among place names, the historical background, the culture and living environment, and the changes over time.

"Silk Road" is an ancient overland commercial trade channel connecting China with Asia, Africa and Europe, formed in the 2nd century BC and has been used until the 16th century. It is the major economic, political and cultural exchanges link of the East and West. In the 13th Century, with the westward expedition of Mongolian, the communication and integration of culture among different countries was accelerated, which led to many Mongolian place-names scattered in the countries along the silk-road, such as Khwarezmia, Armenia, Mesopotamia, Kipchak, Persian, involving today's Russia, Poland, Ukraine, Bulgaria, Hungary, Austria, Italy, Serbia, Syria, Iran, Afghanistan, Iraq, Uzbekistan, Turkmenistan, India and many other countries and regions.

One project has been conducted by the authors of this paper, together with experts from surveying and mapping agencies. The Chinese Mandarin place names in China and Cyrillic Mongolian place names in Mongolia had been collected and translated into traditional Mongolian, which is mostly close to ancient Mongolian. A digital map been developed and published, with the place names in current Chinese Mandarin, Cyrillic Mongolian and traditional Mongolian. Many local people in different part of China have been invited to review and verify the translated traditional Mongolian place names. Some analyse on the distribution of Mongolian place names, and its relationship with the residential and transition places of Mongolian people had been made.

\section{TECHONOLOGY PATHWAY}

The following works had been done by the group

(1) Collect current place names. After analysis, the place names were divided in to the following kinds:

i. Original from Mongolian

ii. Original from Mandarin language

iii. Original from other languages, such as Uygur, Tibetan, etc.

(2) Study the method of translation and defined the rule of translation. Different translation methods were used for different kinds of place names. For those original from Mandarin language, a machine translation tool was developed based on syllable translation. For those original from Mongolian, the corresponding traditional Mongolian place names should be found out. The most difficult are those original from other languages. We need first to find out the names in the original language, and then 
translated it into the traditional Mongolian. A database had been established to maintain translated place names, and the related original place names, as well as some referenced documents.

(3) Study the method for symbolization of the traditional Mongolian on the web-based map. Web services in WMTS and WFS protocols were released, with the traditional Mongolian place names on the map. A switch between traditional Mongolian, Chinese Mandarin and Cyrillic Mongolian was provided to the users.

(4) A tool had been developed and published in the website to let volunteer local people to review and verity the translation.

\section{PROGRESS OF THE STUDY}

Totally 112, 460 Chinese Mandarin place names in China, and 7500 Cyrillic Mongolian place names in Mongolia had been translated and published in the website, as shown in the following figures. The website have been used for integration of different along the "Silk Road".

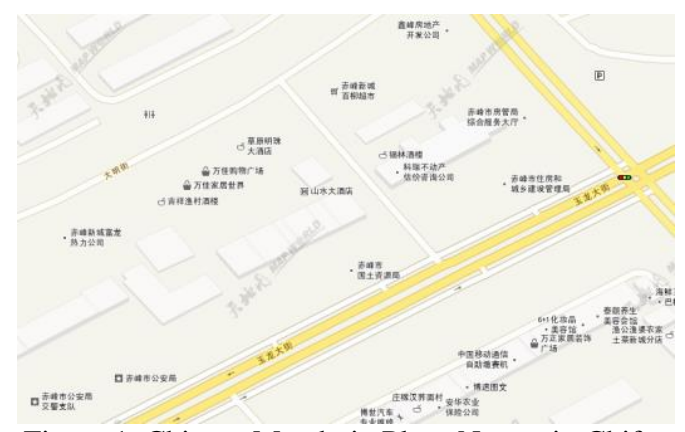

Figure 1. Chinese Mandarin Place Names in Chifen City, China

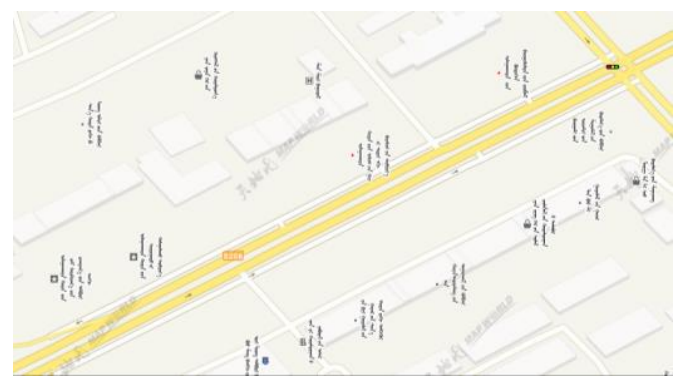

Figure 2. Traditional Mongolian Place Names in Chifen City, China

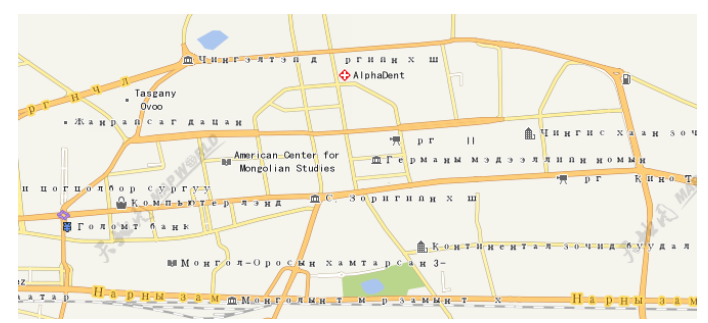

Figure 3. Cyrillic Mongolian place names in Ulaanbaatar, Mongolia

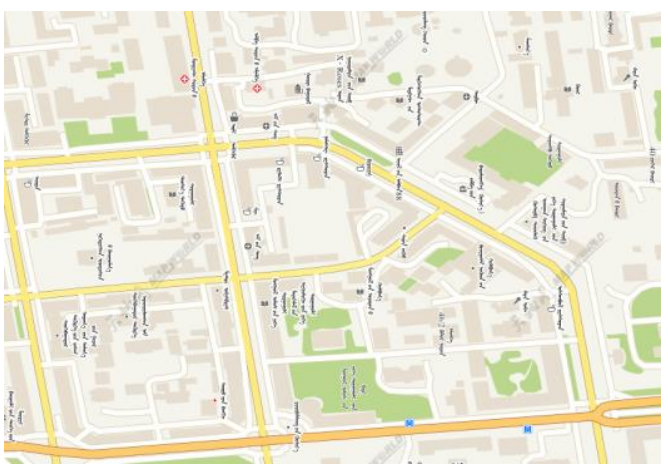

Figure 4. Traditional Mongolian place names in Ulaanbaatar, Mongolia

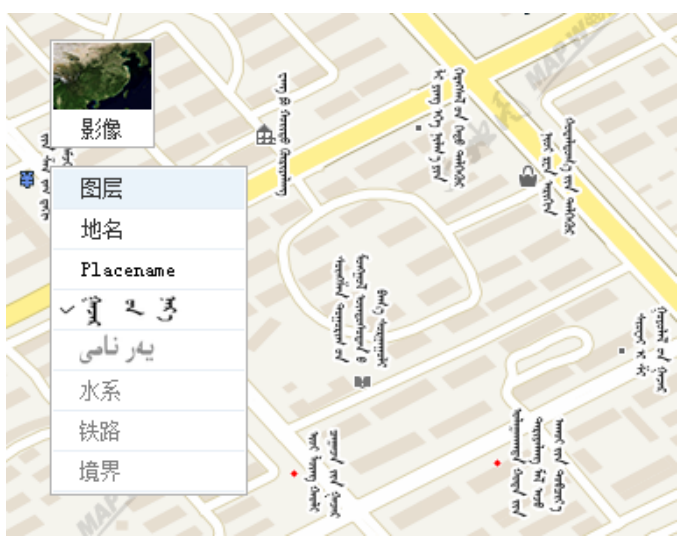

Figure 5. Switch Among Different Languages

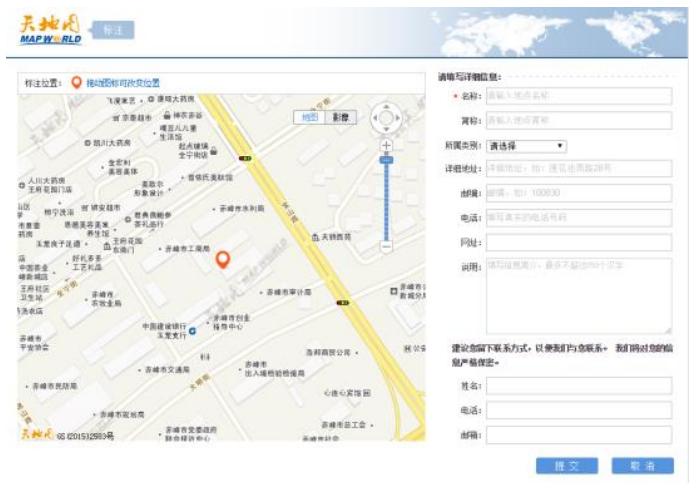

Figure 6. On-line Verification Tool

\section{FURTHER STUDY}

The study is now still in the beginning stage. We are enlarging the number of place names in our databases and integrating various information with the map and place names, including the routes towns of the ancient silk road, the social and economic status in history, the migration route of Mongolian tribes, etc. We are going to analyse the inter-relationship of these information and will publish it in the website. And further application will be conducted based on this database. 


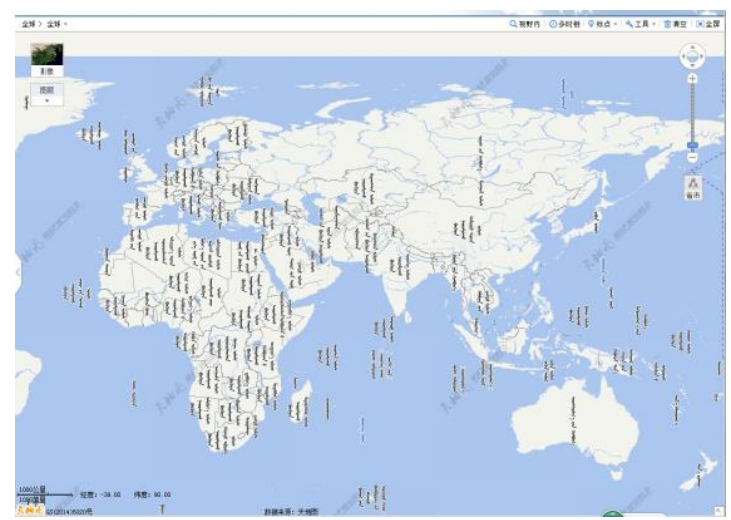

Figure 7. On-line Geospatial Database with Mongolian Place Names

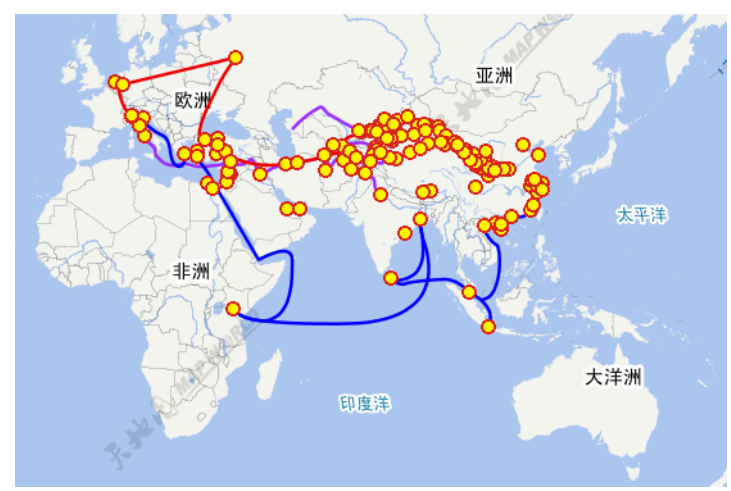

Figure 8. Silk Road and Ancient Towns

\section{REFERENCES}

WANG, W. P. , 1981, To explore the structure and meaning of the Mongolian place names, Journal of Nanjing Normal University, 1981(2), pp 84-89

Yierjian, 1991, Place Name in Mongolica, Mongolia Information, 1991(3), pp 64-65

Hadanchaolu, 2010, Brief Introduction to the Study of Mongolian Place Names, Chinese Place Name 2010(10), pp 42-43

Bai, C. S., Mia, C. 2011, The Characteristics of Mongolian Place Names in Inner Mongolia and the Translation Rules, Journal of Inner Mongolia University for Nationalities, 2011(4) 